\title{
Theaceae endémicas del Perú
}

\section{Blanca León ${ }^{1,2}$}

${ }^{1}$ Museo de Historia Natural, Av. Arenales 1256, Aptdo. 14-0434, Lima 14, Perú

2 Plant Resources Center, University of Texas at Austin, Austin TX 78712 EE.UU.

blanca.leon@mail.utexas.edu

\section{Resumen}

La familia Theaceae es reconocida en el Perú por presentar cuatro géneros y 26 especies (Brako \& Zarucchi, 1993), todas ellas arbustos y árboles. En este trabajo reconocemos ocho especies endémicas, en tres géneros, incluyendo una especie erróneamente descrita e incluida en el género Symplocos. Estas especies endémicas se encuentran en las regiones Bosques Muy Húmedos Premontanos, Bosques Muy Húmedos Montanos y Bosques Húmedos Amazónicos, entre los 100 y 3000 m de altitud; dos de ellas están representadas dentro del Sistema Nacional de Áreas Naturales Protegidas por el Estado.

Palabras claves: Theaceae, Perú, endemismo, plantas endémicas.

\section{Abstract}

The Theaceae are represented in Peru by four genera and 26 species (Brako \& Zarucchi, 1993), all trees and shrubs. Here we recognize eight endemic species in three genera, including an erroneously described species attributed to the genus Symplocos. Endemic Theaceae species are found in Very Humid Premontane Forests, Very Humid Montane Forests and Humid Lowland Amazonian Forests regions, between 100 and $3000 \mathrm{~m}$ elevation. Two endemic species have been recorded in the Peru's protected areas system.

Keywords: Theaceae, Peru, endemism, endemic plants.

\section{Freziera ferruginea Wawra}

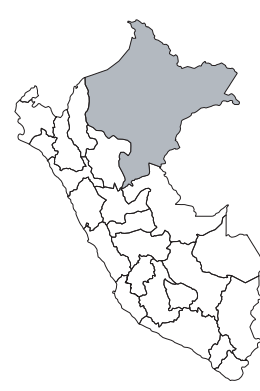

\section{EN, B1ab(iii)}

Publicación: Fl. Bras. 12(1): 284. 1896. Colección tipo: R. Spruce 4442

Herbarios: NY.

Nombre común: Desconocido.

Registro departamental: LO, SM.

Regiones Ecológicas: BMHP; altitud desconocida.

SINANPE: Sin registro.

Herbarios peruanos: Ninguno.

Observaciones: Esta especie arbórea se conoce de dos localidades en el nor oriente del país. Jørgensen \& León Yánez (1999) indicaron que reportes de esta especie en Ecuador, se basaron en identificaciones erradas. No ha vuelto a ser recolectada, al parecer, desde 1903. Ocupa ambientes premontanos, donde sus poblaciones están fuertemente afectadas por la deforestación. Probablemente esté representada en el Bosque de Protección del Alto Mayo.

\section{Freziera parva Kobuski}

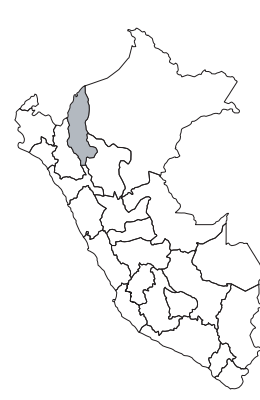

\section{CR, B1ab(iii)}

Publicación: J. Arnold Arbor. 22: 485. 1941.

Colección tipo: A. Weberbauer 7152

Herbarios: US.

Nombre común: Desconocido.

Registro departamental: AM.

Regiones Ecológicas: BMHM; 2900$3000 \mathrm{~m}$.

SINANPE: Sin registro.

Herbarios peruanos: Ninguno.

Observaciones: Este arbusto se conoce de la cuenca del Chiriaco. Brako \& Zarucchi (1993) listaron Cusco, en la distribución departamental de esta especie, pero no pudo verificarse. La localidad original, cuenta con remanentes de bosque fuertemente afectados por la deforestación.

\section{Freziera spathulifolia (Melchior) Kobuski}

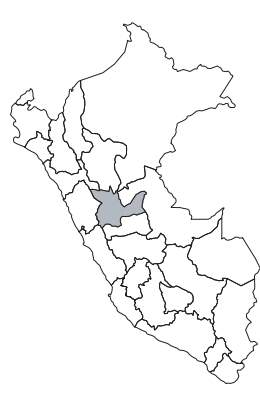

\section{CR, B1ab(iii)}

Publicación: Ann. Missouri Bot. Gard. 25: 355. 1938.

Colección tipo: A. Weberbauer 3423

Herbarios: B; MOL!

Nombre común: Desconocido.

Registro departamental: HU.

Regiones Ecológicas: BMHM; $2400 \mathrm{~m}$.

SINANPE: Sin registro.

Herbarios peruanos: MOL (isotipo).

Observaciones: Esta especie arbustiva, se conoce solamente de una localidad, en la cuenca del río Monzón, donde, al parecer, no ha vuelto a ser recolectada desde 1903. Esa cuenca alberga varios endemismos, pero carece de estudios botánicos recientes; tanto la cuenca del Huallaga, como la de su tributario,el Monzón, presentan fragmentación alta de sus bosques.

\section{Symplocos compacta J.F. Macbr.}

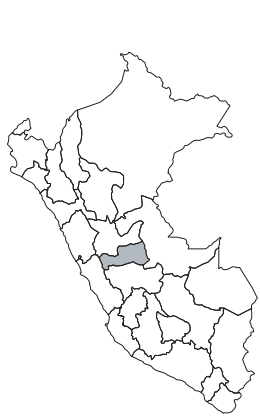

\section{DD}

Publicación: Candollea 5: 399. 1934.

Colección tipo: A. Weberbauer 6731

Herbarios: F, US.

Nombre común: Desconocido.

Registro departamental: PA.

Regiones Ecológicas: BMHM; 2200$2900 \mathrm{~m}$.

SINANPE: Sin registro.

Herbarios peruanos: Ninguno. 


\section{Ternstroemia globiflora Ruiz \& Pav.}

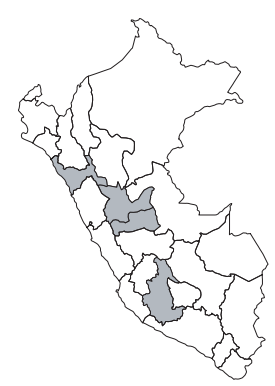

\section{VU, B1a}

Publicación: Syst. Veg. Fl. Peruv. Chil. 179. 1798.

Colección tipo: H. Ruiz \& J. Pavón s.n.

Herbarios: MA.

Nombre común: Desconocido.

Registro departamental: AY, HU, LL, PA.

Regiones Ecológicas: BMHM, BMHP; 1300-2100 m.

SINANPE: Sin registro.

Herbarios peruanos: MOL (1).

Observaciones: Esta especie arbórea o arbustiva, se conoce de cuatro localidades aisladas, en bosques de la vertiente oriental del país; dos de las localidades están ubicadas relativamente cerca de dos Parques Nacionales, Abiseo y Yanachaga-Chemillén. Probablemente se encuentre en otros bosques montanos en San Martín y Huánuco escasamente herborizados.

\section{Ternstroemia klugiana Kobuski}

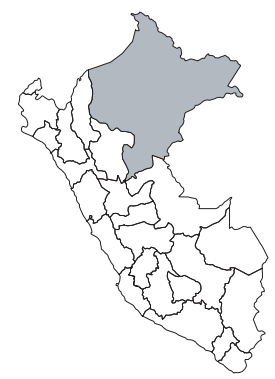

\section{VU, B1ab(iii)}

Publicación: J. Arnold Arbor. 23: 334. 1942.

Colección tipo: G. Klug 64

Herbarios: GH, US.

Nombre común: Carach caspi.

Registro departamental: LO.

Regiones Ecológicas: BHA; $100-140$ m. SINANPE: RNAM

Herbarios peruanos: AMAZ (7), USM (2).

Observaciones: Especie arbórea conocida de por lo menos cinco localidades, en los alrededores de Iquitos. Vásquez (1997) indica que esta especie crece sobre suelos arenosos, probablemente sea especialista de este tipo de suelos. Las poblaciones conocidas provienen mayormente de la Reserva Nacional Allpahuayo-Mishana. Los bosques de arena blanca están naturalmente fragmentados y los cercanos a esta reserva están afectados por desarrollo urbano.

\section{Ternstroemia pachytrocha Kobuski}

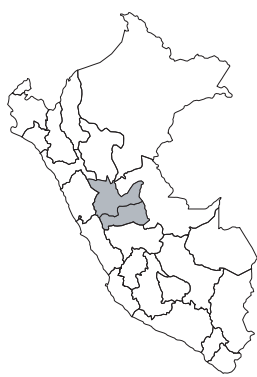

\section{EN, B1ab(iii)}

Publicación: J. Arnold Arbor. 23: 320. 1942.

Colección tipo: R. Kanehira 44

Herbarios: GH.

Nombre común: Desconocido.

Registro departamental: HU, PA.

Regiones Ecológicas: BMHM, BMHP; $2100 \mathrm{~m}$.

SINANPE: Sin registro,

Herbarios peruanos: Ninguno.

Observaciones: Esta especie arbórea se conoce de dos localidades, en el centro del país; al parecer, no ha vuelto a ser recolectada desde 1983. La localidad original está ubicada en la cuenca media del Huallaga, la cual está afectada por la deforestación.

\section{Ternstroemia penduliflora Kobuski}

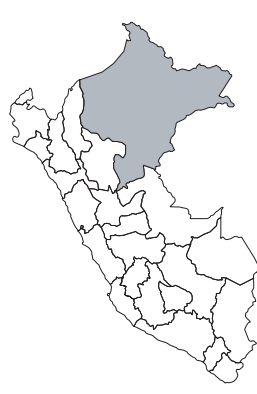

\section{VU, B1a}

Publicación: J. Arnold Arbor. 23: 311. 1942.

Colección tipo: G. Klug 1487

Herbarios: GH, NY, US.

Nombre común: Camé, renaco.

Registro departamental: LO.

Regiones Ecológicas: BHA; 100—122 m. SINANPE: RNAM

Herbarios peruanos: AMAZ (12).

Observaciones: Esta especie arbórea se conoce de, por lo menos, cinco localidades y numerosas colecciones realizadas principalmente cerca de Iquitos, donde habita meandros antiguos (cochas). Una población está ubicada en la Reserva Nacional Allpahuayo-Mishana. 